\title{
Long-Term Effect of Biological Soil Disinfestation on Verticillium Wilt
}

\author{
Jan-Kees C. Goud, Aad J. Termorshuizen, Wim J. Blok, and Ariena H. C. van Bruggen, Biological Farming Sys- \\ tems Group, Wageningen University, Marijkeweg 22, 6709 PG Wageningen, the Netherlands
}

\begin{abstract}
Goud, J. C., Termorshuizen, A. J., Blok, W. J., and van Bruggen, A. H. C. 2004. Long-term effect of biological soil disinfestation on Verticillium wilt. Plant Dis. 88:688-694.

Biological soil disinfestation (BSD), involving incorporation of grass combined with plastic mulching, eliminates many soilborne pests and diseases through the creation of anaerobic conditions. BSD was compared at two locations with a nontreated control, Italian ryegrass amendment alone, and plastic mulch alone. After the soil treatments, plots were cropped with Acer platanoides and Catalpa bignonioides and grown for 4 years. Relative to the control, soil inoculum levels of Verticillium dahliae were reduced by $85 \%$ after BSD and did not increase for 4 years. Populations of Pratylenchus fallax, known for their interaction with $V$. dahliae, in the soil and in roots were reduced by 95 to $99 \%$. The incidence of infection by $V$. dahliae was reduced by 80 to $90 \%$. Verticillium wilt severity was significantly reduced in A. platanoides in all 4 years at one location and in the first 2 years at the other location, and significantly fewer plants died at one location. Shoot length and trunk width were larger after BSD compared with the control at one location. Market value of the crop in BSD plots was up to $€ 140,000 \mathrm{ha}^{-1}$ higher for A. platanoides and up to $€ 190,000$ ha $^{-1}$ higher for C. bignonioides than in the untreated control. BSD is an effective, economically profitable, and environmentally friendly control method for tree nurseries.
\end{abstract}

Additional keywords: disease management, methyl bromide alternative, Norway maple, plant pathogenic nematodes, southern catalpa

Verticillium wilt, caused by the soilborne fungus Verticillium dahliae Kleb., occurs in many crops all over the world. The disease can be a severe problem in potato, strawberry, and olive production, and in nurseries for strawberries and ornamental trees $(18,22)$. In tree nurseries, losses up to $50 \%$ have been reported (1). Interactions of $V$. dahliae with plantpathogenic nematodes have been observed in potato $(14,24)$ and sugar maple (Acer saccharum Marshall) (9). A recent study has shown that Pratylenchus fallax Seinhorst can contribute to Verticillium wilt in Norway maple (A. platanoides L.) at low inoculum densities of $V$. dahliae (10).

Until recently, effective control of $V$. dahliae and plant-pathogenic nematodes was achieved by fumigating the soil with chemicals, but restrictions in the use of soil fumigants will necessitate nonchemical alternatives. In developed countries, the application of methyl bromide will be prohibited by 2005, and in developing

Corresponding author: Jan-Kees Goud

E-mail: jankees.goud@wur.nl

Accepted for publication 25 February 2004.

Publication no. D-2004-0428-01R

(C) 2004 The American Phytopathological Society countries in 2015 (8). In the Netherlands, the application of methyl bromide has been banned since 1992, after a 10 -year phaseout period (16). Currently, metham sodium is the only liquid soil fumigant allowed in the Netherlands, and its use is restricted throughout the country to a maximum of once every 5 years. Metham sodium and 1,3-dichloropropene, which are effective against nematodes, are only slightly effective on plant-pathogenic fungi. Effective nonchemical methods of control exist, but their application is often limited to certain cropping systems. Steaming the soil requires high investment and therefore is only applied in high-value crops (7). Soil solarization (13) and flooding (23) can reduce inoculum levels of soilborne pathogens $(2,19)$, but solarization is restricted to warmer areas, and flooding is not feasible in most locations.

Recently, biological soil disinfestation (BSD) was reported by Blok et al. (3) to be a promising alternative for reducing soil inoculum levels of a wide variety of plantpathogenic soilborne fungi (3) and nematodes (W. J. Blok, J. G. Lamers, G. C. M. Coenen, and A. J. Termorshuizen, unpublished). BSD combines the incorporation of fresh organic amendments in soil and mulching with airtight plastic. This combination creates an anaerobic condition in the soil that results in pathogen elimina- tion. BSD is different from solarization, because the death of pathogens is not caused by high temperatures (3). The method has been proven effective in several large-scale field experiments and is advocated for use in high-value crops. It has broad-spectrum activity against many soilborne fungi and plant-pathogenic nematodes, and is similar to methyl bromide in efficacy $(3,21$; W. J. Blok, J. G. Lamers, G. C. M. Coenen, and A. J. Termorshuizen, unpublished).

Soil disinfestation, either chemical or nonchemical, introduces the potential risk of lowering the general soil suppressiveness toward pathogens by disturbing the soil microflora (23). V. dahliae is unable to grow through nonrhizosphere soil because of inhibition by the general microbial soil community, but it can actively colonize sterilized soil (23). Therefore, the possibility exists that BSD may reduce numbers of general or specific antagonists, and thus confer conduciveness to the treated soil.

The objectives of the present study were (i) to investigate the effectiveness of BSD in reducing soil inoculum levels of $V$. dahliae and plant-pathogenic nematodes, and (ii) to determine whether there was an increase in disease conduciveness for Verticillium wilt in tree nurseries after BSD.

\section{MATERIALS AND METHODS}

Plot arrangement. To test the efficacy and persistence of BSD against $V$. dahliae, a $2 \times 2$ factorial field experiment in a randomized complete block design with five replications was conducted at Wageningen (experimental farm of Wageningen University, province of Gelderland, the Netherlands) in 1997 and at Meterik (experimental farm "Meterikse Veld", province of Limburg, the Netherlands) in 1998. Experimental factors were (i) with or without the incorporation of freshly mown Italian ryegrass (Lolium multiflorum Lam.) at 40 to $54 \mathrm{t} \mathrm{ha}^{-1}$, and (ii) with or without covering the field with nearly airtight plastic. After the treatments, the soil was left fallow till the next spring, when seedlings of Acer platanoides L. (Norway maple) and Catalpa bignonioides Walt. (southern catalpa) were planted. The severity of Verticillium wilt and soil inoculum densities of $V$. dahliae were followed for 4 years after treatment. Plots measured $8 \times 8 \mathrm{~m}$ (Wageningen) or $7.5 \times 10.5 \mathrm{~m}$ (Meterik). 
To avoid plot border effects, measurements were performed only in the inner area of each plot, measuring $5 \times 5 \mathrm{~m}$ (Wageningen) or $4.5 \times 7.5 \mathrm{~m}$ (Meterik).

Field characteristics and infestation. The soil at Wageningen was a loamy sand ( 0 to $20 \mathrm{~cm}$ soil layer: $\mathrm{pH}-\mathrm{CaCl}_{2}=5.8$, organic matter $=3.3 \% ; 30$ to $60 \mathrm{~cm}$ soil layer: $\mathrm{pH}-\mathrm{CaCl}_{2}=5.7$, organic matter $=$ $1.9 \%$ ) that was cropped with potato in the year prior to the experiment. The inoculum level of $V$. dahliae was $3.0 \mathrm{CFU} \mathrm{g}^{-1}$ dry soil weight. At Meterik, a field (loamy sand, 0 to $20 \mathrm{~cm}$ soil layer: $\mathrm{pH}-\mathrm{CaCl}_{2}=$ 4.9 , organic matter $=2.8 \% ; 30$ to $60 \mathrm{~cm}$ soil layer: $\mathrm{pH}-\mathrm{CaCl}_{2}=5.0$, organic matter $=2.2 \%$ ) that was cropped with Tagetes $\mathrm{sp}$. for 2 years prior to the experiment was artificially infested with $V$. dahliae from potato stems.

Potato stems covered with microsclerotia were collected in October 1997 from various agricultural fields in the provinces of Drenthe and Gelderland (the Netherlands). The density of microsclerotia was approximately 1 million microsclerotia per gram of dried potato stem, and was assessed by milling a random sample of the dried potato stems, suspending the milled tissue in $0.08 \%$ water agar, and counting the microsclerotia in small aliquots under the microscope. The stems were air-dried and stored during winter at 5 to $10^{\circ} \mathrm{C}$, milled with a cutting mill (SM2000, Retsch, Haan, Germany) using a $1.0-\mathrm{mm}$ screen shortly before application, and mixed 1:1 (vol/vol) with sand. Approximately $15 \mathrm{~g}$ of potato stem tissue $\mathrm{m}^{-2}$ was spread by hand over the plot and mixed into the top 20- to $25-\mathrm{cm}$ soil layer using a rototiller on 1 May 1998.

Soil treatments. Soil treatments were applied at Wageningen in the summer of 1997 and at Meterik in the summer of 1998, as described by Blok et al. (3). At Wageningen, freshly mown young grass $(\mathrm{C} / \mathrm{N}$ ratio $=13.9)$ from a production pasture was applied and mixed into the top $25-\mathrm{cm}$ soil layer at 40 tons fresh weight $\mathrm{ha}^{-1}\left(=4.56\right.$ tons oven dry weight $\left.\mathrm{ha}^{-1}\right)$ on 8 July 1997 . At Meterik, grass $(\mathrm{C} / \mathrm{N}$ ratio $=$ 21.4) was sown on the experimental plots on 11 May 1998 and incorporated into the top $35-\mathrm{cm}$ soil layer on 3 August. At the time of incorporation, the biomass (shoots + roots) was 54 tons fresh weight ha ${ }^{-1}$ (= 15.4 tons oven dry weight ha ${ }^{-1}$ ). Soil in all amended and control plots was rototilled, compacted with a tractor, and irrigated with approximately 50 to $70 \mathrm{~mm}$ of water using overhead sprinklers. The tarped plots were covered with three-layered ensilage plastic with low oxygen permeability. At Wageningen, the plastic was $0.135-\mathrm{mm}-$ thick Hytileen (Klerks Plastic Industrie, Noordwijkerhout, the Netherlands), black on top and white on the bottom. At Meterik, the plastic was $0.115-\mathrm{mm}$-thick Hermetix (Klerks Plastic Industrie, Noordwijkerhout, the Netherlands), green on top and white on the bottom. The edges of the cover were buried approximately 10 $\mathrm{cm}$ deep. The plastic cover was present from 11 July to 10 October 1997 (13 weeks) at Wageningen and from 6 August to 13 October 1998 (10 weeks) at Meterik. After removal of the plastic covers, the soil was left fallow for 6 months until the next spring.

Assessment of soil inoculum levels of $\boldsymbol{V}$. dahliae. To determine preplanting inoculum levels of $V$. dahliae, 50 soil cores (0 to $25 \mathrm{~cm}$ deep) were collected per plot in a $\mathrm{V}$ and inverse- $\mathrm{V}$ pattern. Soil samples from a plot were thoroughly mixed and stored at $4^{\circ} \mathrm{C}$ until processed. A subsample of the soil was air-dried at room temperature, dry-sieved through a 2-mm sieve, and $12.5 \mathrm{~g}$ of the air-dry soil was subsequently wet-sieved through 106- and 20- $\mu$ m nested sieves. The fraction retained on the $20-\mu \mathrm{m}$ sieve was suspended in $50 \mathrm{ml}$ of $0.08 \%$ water agar, and $0.8 \mathrm{ml}$ of this suspension was plated on modified soil extract agar (MSEA), a semiselective medium (12) containing soil extract prepared from a sandy garden soil and 50 ppm oxytetracycline. After incubation at $20^{\circ} \mathrm{C}$ for 4 weeks, colonies were counted and $\mathrm{CFU} \mathrm{g}{ }^{-1}$ dry soil were calculated. Postplanting soil inoculum levels of $V$. dahliae were assessed similarly each spring, except that samples were collected within the planted rows approximately $15 \mathrm{~cm}$ from the base of the trees. Soil samples were taken separately for maple and catalpa, except for the second year in Wageningen, where soil samples from the two plant species were pooled per plot.

Assessment of nematode populations. At Wageningen, soil inoculum densities of free-living plant-pathogenic nematodes were assessed in the soil samples that were kept at $4^{\circ} \mathrm{C}$ and used for assessment of soil inoculum levels of $V$. dahliae. A 200-g subsample was washed in an Oostenbrink elutriator (17), and the nematodes and lighter soil particles were caught on four 45- $\mu \mathrm{m}$ sieves and washed onto a filter (Milac cotton sandwich, diameter $22 \mathrm{~cm}$; Hygia/Hartmann, Nijmegen, the Netherlands). The filter was placed in a saucer filled with water, so that the filter was just below water level. The filter was left undisturbed for $24 \mathrm{~h}$, which allowed free-living nematodes to crawl through the filter and be caught on the bottom of the saucer. In a subsample under the microscope, nematodes were identified morphologically to the genus level and counted. The following genera were present: Pratylenchus, Tylenchorhynchus, Trichodorus, Aphelenchus, and Helicotylenchus. In Meterik, plantpathogenic nematodes were not present in the soil, presumably because of two consecutive croppings of Tagetes sp. in the years prior to the experiment.

At Wageningen, number of $P$. fallax per gram of root was determined during the first growing season on a sample of roots pooled from five plants arbitrarily chosen from the row that was removed. A 50-g (fresh weight) subsample was used by cutting the clean roots into approximately $1-\mathrm{cm}$ pieces, placing them in a mist incubator, collecting the nematodes in the runoff for 7 days, and counting them under the microscope (17). During the second season, $P$. fallax was assessed in roots of four arbitrarily selected plants, which were harvested on the same day and analyzed separately using the procedure described above, but with 20 to $30 \mathrm{~g}$ (fresh weight) of roots per plant.

Plant origin and maintenance. Seeds of maple were obtained from Boevé BV (Boskoop, the Netherlands) for the Wageningen experiment, and germinated seeds for the Meterik experiment were obtained from the municipal plant nursery of Wageningen (Wageningen, the Netherlands). Seeds of catalpa were obtained from Boevé BV for both locations. Plants were raised in the greenhouse for 10 weeks and transplanted into the field 7 months after the soil treatments. In Wageningen, each plot was planted with three rows of 20 maple seedlings ( 8 to 10 leaves) and three rows of 20 catalpa seedlings (6 to 8 leaves). At planting, rows were $33 \mathrm{~cm}$ apart, and the plants were spaced at $25-\mathrm{cm}$ intervals. Each set of three rows was surrounded by a row of the same species. After the first growing season, the middle row was harvested to provide growing space for the remaining plants and for assessment of infection. After the second growing season, a second row was removed.

In Meterik, 7 months after the soil treatments, 60 seedlings of each species were planted in each plot in two rows (50 $\mathrm{cm}$ apart) of 30 plants of each species. One row was harvested after the first growing season, and plants were thinned alternately in the second row after the second growing season. After the shoot length measurements in the second year at Meterik and the third year at Wageningen and Meterik, the tops of the plants were cut at $1.80 \mathrm{~m}$ (unless they were shorter) with a pruning knife to achieve a higher and more profitable width/height ratio. This is common practice by growers to prevent trees from becoming too slender. Plants were fertilized twice with $75 \mathrm{~kg} \mathrm{~N}^{-1}\left(50 \% \mathrm{NO}_{3^{-}}\right.$ $\mathrm{N} / 50 \% \mathrm{NH}_{4}$ ) and once with $100 \mathrm{~kg} \mathrm{Mg} \mathrm{ha}{ }^{-1}$ during each growing season. Weeding was done mechanically or by hand at regular intervals. Maple plants were sprayed periodically with fungicides to control mildew (three times with Rubigan, $20 \mathrm{ml}$ per 100 liters of water [Dow Elanco, Wilrijk, Belgium]; twice with Meltatox, $250 \mathrm{ml}$ per 100 liters [BASF, Arnhem, the Netherlands]; and three times with Baycor Flow, $60 \mathrm{ml}$ per 100 liters [Bayer, Mijdrecht, the Netherlands]).

Wilt symptoms. Disease severity was rated monthly during summer and autumn 


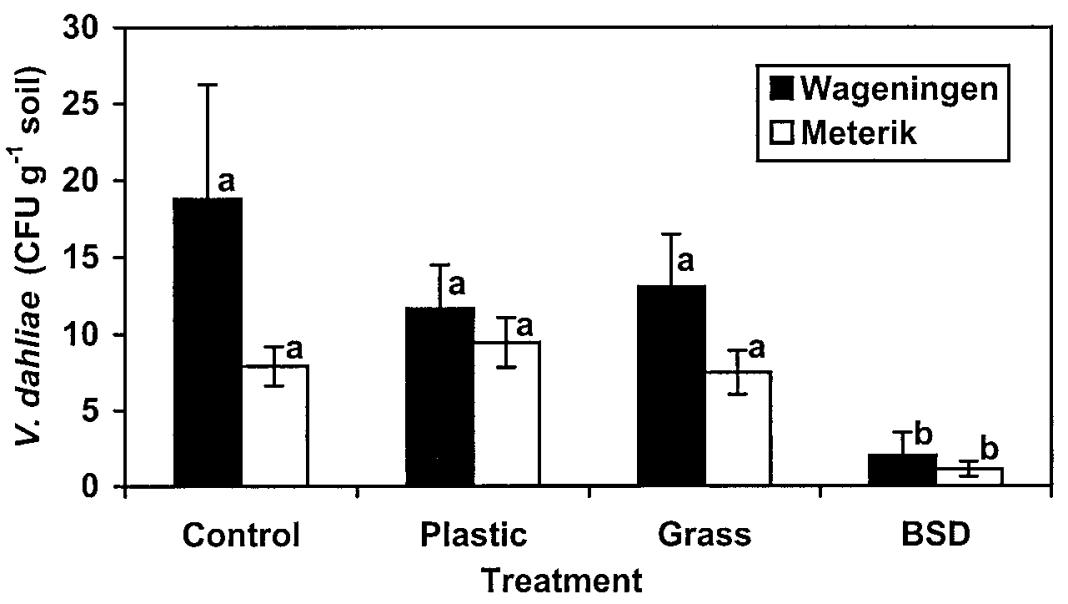

Fig. 1. Effects of the four treatments (control, plastic mulching, grass amendment, and biological soil disinfestation [BSD; grass amendment combined with plastic mulching]) on soil inoculum level (CFU g ${ }^{-1}$ soil) of Verticillium dahliae in the spring in tree nursery plots at Wageningen and Meterik. Error bars indicate standard error of the mean. Bars topped by different letters within a location are significantly different $(P<0.01)$. for 4 years on each plant using a 0 to 5 scale, where $0=$ healthy, $1=$ up to $5 \%$ leaves showing wilt, $2=5$ to $40 \%$ wilt or defoliation, $3=40$ to $60 \%$ wilt or defoliation, $4=60$ to $80 \%$ wilt or defoliation, and $5=$ more than $80 \%$ wilt or defoliation or plant dead. Area under the disease progress curve (AUDPC) values (4) were calculated per plot for each plant species for each growing season. Plants that died during 1 year were included in the disease assessment of that year, but not in disease assessments of following years. Dead trunks of trees that died back during 1 year and regrew from the base during following years were not included in the disease ratings of the following years.

Infection with $\boldsymbol{V}$. dahliae. After the first growing season in Wageningen, the incidence of infection with $V$. dahliae was assessed on all 20 plants of each plant

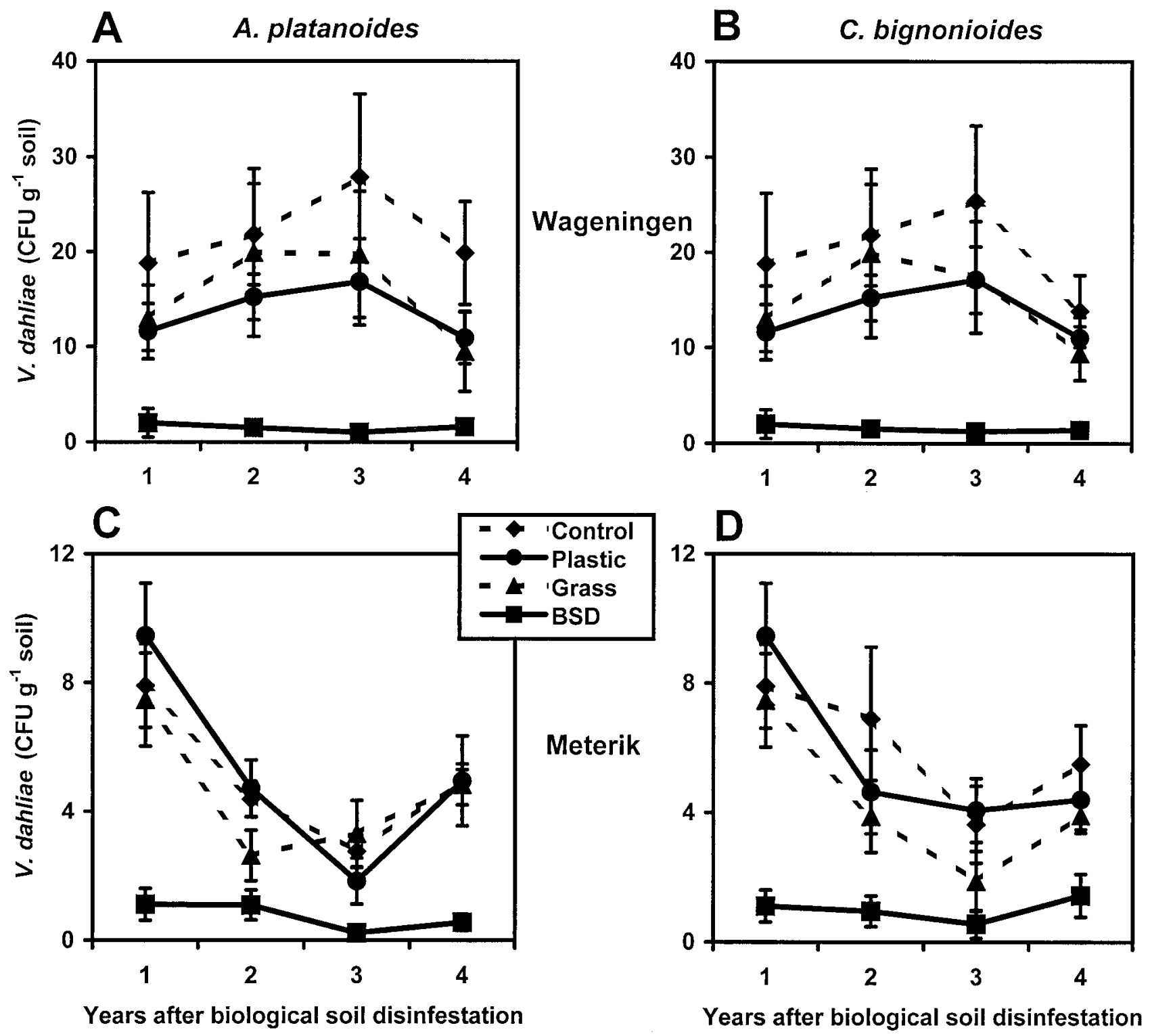

Fig. 2. Inoculum densities of Verticillium dahliae of the four treatments (control, plastic mulching, grass amendment, and biological soil disinfestation [BSD; grass amendment combined with plastic mulching]) during the four consecutive years after the soil treatments (preplanting and after 1,2, and 3 years). A, Acer platanoides in Wageningen; B, Catalpa bignonioides in Wageningen; C, A. platanoides in Meterik; D, C. bignonioides in Meterik. Soil samples were analyzed separately for A. platanoides and C. bignonioides after the first (Meterik) or second (Wageningen) year. Error bars indicate standard error of the mean. 
species that were removed. Plants were harvested by blocks. Blocks 1 to 5 were harvested in 1998 on 9 September, 25 September, 19 October, 29 October, and 10 November, respectively. Infection was confirmed by surface sterilizing the base of the main trunk in $1 \%$ sodium hypochlorite for $1 \mathrm{~min}$, washing in sterile water, aseptically removing the bark, cutting disks with a pruning knife, and placing five to seven disks per tree onto MSEA. After incubation for 4 weeks at $20^{\circ} \mathrm{C}$, presence of $\mathrm{V}$.

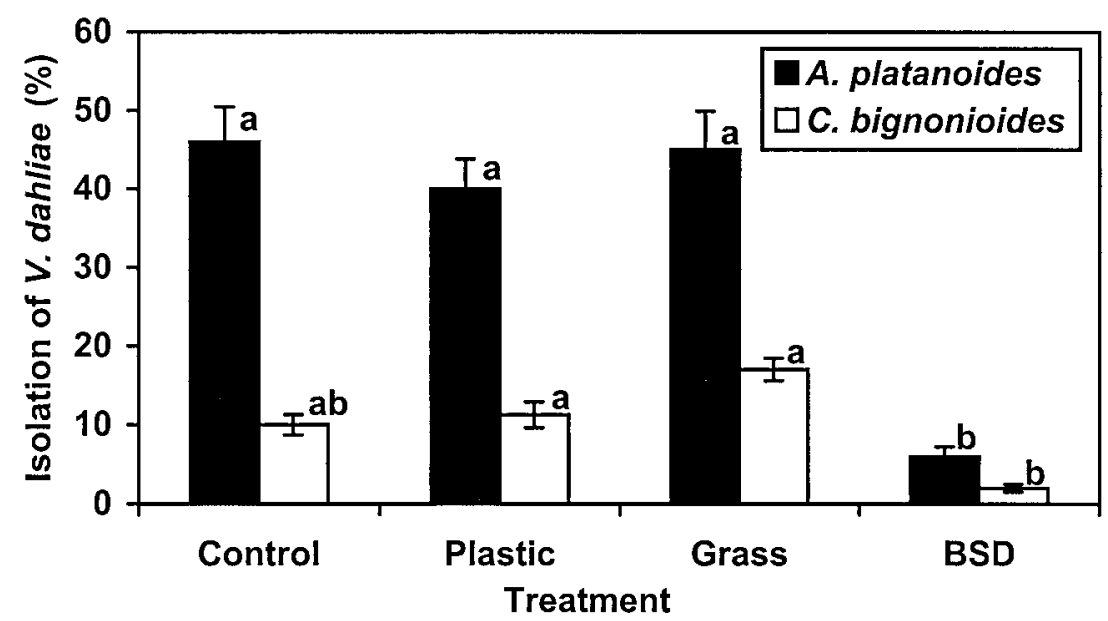

Fig. 3. Effects of the four treatments (control, plastic mulching, grass amendment, and biological soil disinfestations [BSD; grass amendment combined with plastic mulching]) on percentage of isolation of Verticillium dahliae from shoots of Acer platanoides and Catalpa bignonioides plants at the end of the first growing season (Wageningen location only). Error bars indicate standard error of the mean. Bars topped by different letters within a location are significantly different $(P<0.05)$.

dahliae was determined. In Meterik, confirmation of infection by plating was sought only incidentally, when symptoms were unclear.

Shoot length and trunk width. At each location, shoot length was measured at the end of each growing season. Trunk width was measured at the base of each plant after the first (Wageningen and Meterik) and second (Wageningen) growing seasons, and at 1-m height after the following growing seasons. Plants that had died during previous years were not measured. At the end of the experiment, market value was calculated for each original plant in the remaining row, based on absence of wilt symptoms during the 4-year period and size class (trunk width) of the plant. Trunk circumferences at $1-\mathrm{m}$ height were calculated from trunk widths, and plants were grouped into circumference classes. Current advisory prices were used for the different circumference classes of the two species. For maple, these prices are $€ 0,6$, 8,13 , and 20 for the classes $<6,6$ to 8,8 to 10,10 to 12 , and 12 to $14 \mathrm{~cm}$, respectively, and for catalpa these prices are $€ 0$, $10,16,23,30$, and 42 for the classes $<8$, 8 to 10,10 to 12,12 to 14,14 to 16 , and 16 to $18 \mathrm{~cm}$, respectively (H. Meijer, personal communication). Advisory
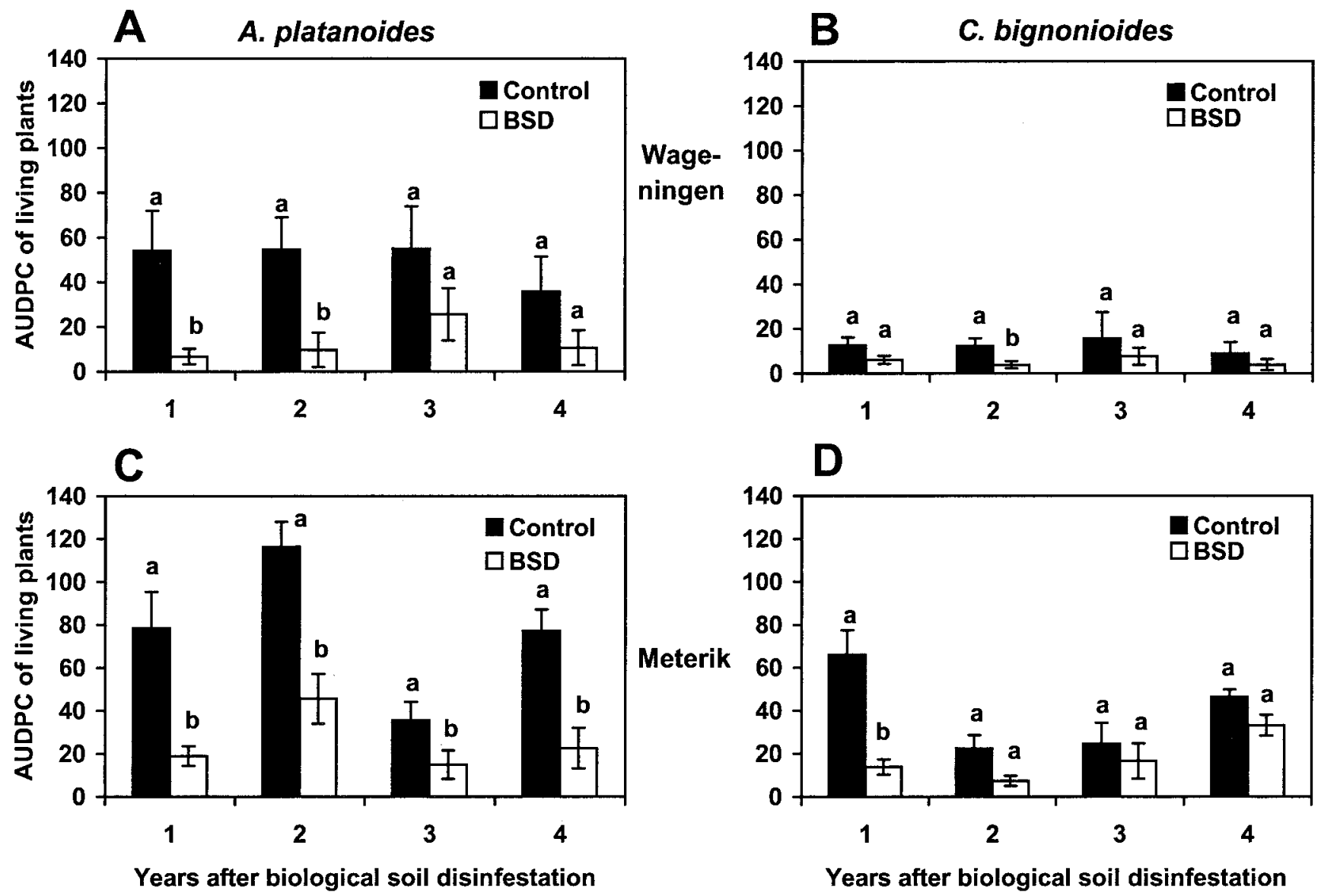

Fig. 4. Area under the disease progress curves (AUDPCs) of biological soil disinfestation (BSD; grass amendment combined with plastic mulching) and the control during the four growing seasons following the soil treatments. A, Acer platanoides in Wageningen; B, Catalpa bignonioides in Wageningen; $\mathbf{C}$, A. platanoides in Meterik; D, C. bignonioides in Meterik. Error bars indicate standard error of the mean. Bars topped by different letters within a location and plant species within a year are significantly different $(P<0.05)$. 
prices for dead or symptomatic plants are zero.

Data analysis. Data were analyzed with SAS version 8.0 (SAS Institute, Inc., Cary, NC). The GLM procedure was used for analysis for inoculum levels of $V$. dahliae and nematodes in the soil, AUDPC values, numbers of $P$. fallax per plant root, shoot length, and trunk width. Soil inoculum numbers of $P$. fallax per gram of plant root were log-transformed, and percentages of diseased and dead plants were arcsinetransformed to obtain normal distribution of residuals. Contrast analyses were performed between the individual treatments. Development of the soil inoculum densilevels of $V$. dahliae and nematodes, and

ties for the different treatments over time was analyzed by regression analysis. Enhanced disease conduciveness was tested by covariance analysis of the data of the BSD treatment and the control. By treating AUDPC values as dependent variable, soil inoculum levels of $V$. dahliae as covariate, and with or without BSD as explanatory variable, effects of BSD on disease were corrected for different $V$. dahliae soil inoculum levels (5).

\section{RESULTS}

Long-term effects of BSD on inoculum densities of $V$. dahliae in the soil. In each field experiment, BSD resulted in an $85 \%$ reduction of the soil inoculum level

Table 1. Significance levels of the contrast analyses between biological soil disinfestation (BSD) and the control treatment for living shoot length, trunk width, and percentage of dead plants at the end of each growing seasons following treatment

\begin{tabular}{|c|c|c|c|c|}
\hline Location and plant species & Year 1 & Year 2 & Year 3 & Year 4 \\
\hline \multicolumn{5}{|l|}{ Shoot length ${ }^{\mathrm{a}}$} \\
\hline Wageningen, Acer platanoides & $0.03^{b}$ & 0.06 & 0.15 & 0.22 \\
\hline Wageningen, Catalpa bignonioides & 0.13 & 0.55 & 0.27 & 0.39 \\
\hline Meterik, A. platanoides & 0.26 & $<0.01$ & $<0.01$ & $<0.01$ \\
\hline Meterik, $C$. bignonioides & $<0.01$ & $<0.01$ & 0.01 & 0.04 \\
\hline \multicolumn{5}{|l|}{ Trunk width ${ }^{\mathrm{a}, \mathrm{c}}$} \\
\hline Wageningen, A. platanoides & 0.14 & 0.20 & 0.11 & 0.11 \\
\hline Wageningen, $C$. bignonioides & 0.95 & 0.76 & 0.43 & 0.06 \\
\hline Meterik, A. platanoides & 0.04 & $<0.01$ & $<0.01$ & 0.01 \\
\hline Meterik, C. bignonioides & $<0.01$ & 0.01 & 0.37 & 0.18 \\
\hline \multicolumn{5}{|l|}{ Percent dead plants ${ }^{\mathrm{d}}$} \\
\hline Wageningen, $A$. platanoides & 0.12 & $<0.01$ & $<0.01$ & $<0.01$ \\
\hline Wageningen, $C$. bignonioides & 0.31 & 1.00 & 0.42 & 0.42 \\
\hline Meterik, A. platanoides & 0.11 & $<0.01$ & 0.02 & 0.06 \\
\hline Meterik, $C$. bignonioides & 0.73 & 0.50 & 0.98 & 0.98 \\
\hline
\end{tabular}

a Shoot length and trunk width of surviving plants (i.e., dead trunks of recovered plants not included).

b Shoot length of A. platanoides plants at end of first year in Wageningen was larger in control plots than in BSD plots. All other significant differences indicate shoot lengths or trunk widths that were larger in BSD plots than in control plots, or percentages of dead plants that were lower in BSD plots than in control plots.

c Trunk width was measured at base of tree after first (Wageningen and Meterik) and second (Wageningen) growing seasons, and at 1-m height after the second (Meterik), third, and fourth growing seasons.

${ }^{\mathrm{d}}$ Recorded during spring following the growing season mentioned.

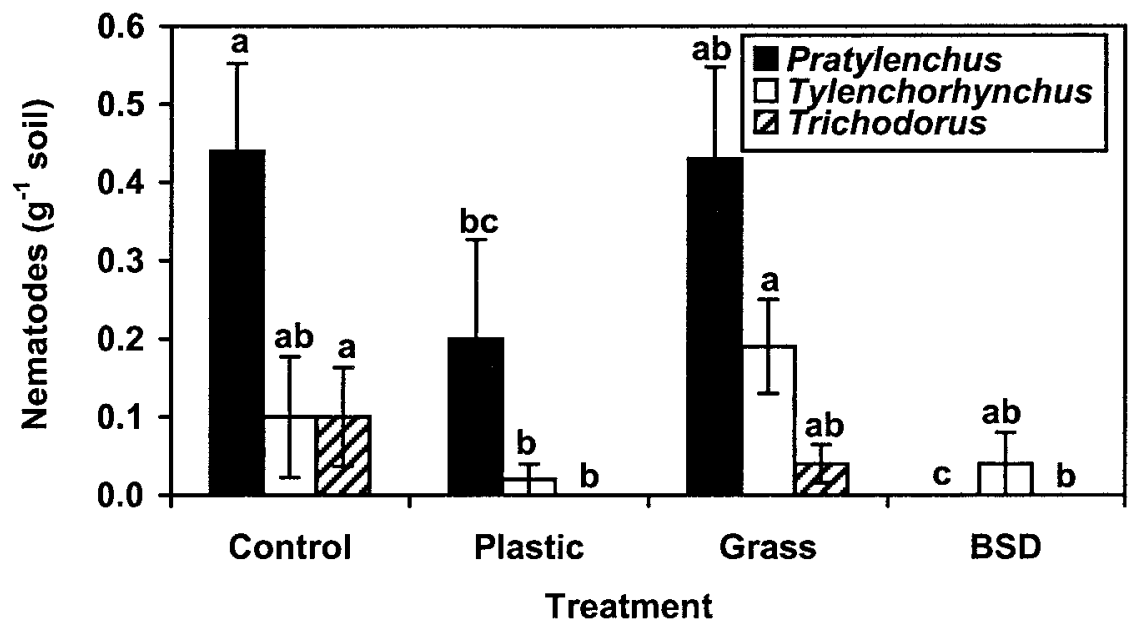

Fig. 5. Effects of the four treatments (control, plastic mulching, grass amendment, and biological soil disinfestations [BSD; grass amendment combined with plastic mulching]) on number of free-living plant-pathogenic nematodes in the spring following treatment in the tree nursery plots (Wageningen location only). Error bars indicate standard error of the mean. Bars topped by different letters within a location are significantly different $(P<0.05)$. of $V$. dahliae compared with the control $(P$ $<0.01)$, while the grass amendment or plastic tarp treatments alone did not significantly lower the inoculum levels (Fig. 1). The interaction between grass amendment and plastic tarp was significant at Meterik $(P<0.01)$, but not at Wageningen $(P=0.06)$.

Inoculum densities of $V$. dahliae (initial and after one, two, and three growing seasons) in the two field experiments for the four treatments and the two plant species are shown in Figure 2. In Wageningen, inoculum levels did not significantly change over the years for all treatments. In Meterik, regression analysis demonstrated a significant decrease over time $(P=0.05)$ in inoculum levels in the plastic tarp plots cropped to catalpa, but not in the other plots. Enhanced recolonization did not occur in the BSD plots. There were no significant differences between soils cropped with maple and catalpa at both locations.

Effect of BSD on plant infection with $V$. dahliae and incidence of Verticillium wilt. As determined by isolation of $\mathrm{V}$. dahliae from the trees, more than $40 \%$ of maple and 10 to $17 \%$ of catalpa trees became infected with $V$. dahliae during the first growing season in the control, grass alone, and plastic alone treatments at Wageningen location (Fig. 3). After BSD, the incidence of infection was reduced by 80 to $90 \%$ compared with the control in maple $(P<$ $0.01)$, but not in catalpa $(P=0.10)$ (Fig. 3). There was a significant interaction between grass amendment and plastic tarp $(P$ $<0.05)$ for both maple and catalpa.

AUDPC values in BSD plots were significantly lower than the control for maple in Meterik during all experimental years and in Wageningen during the first 2 years (Fig. 4). For catalpa, the contrast between BSD and the control was significant only in the first year in Meterik and the second year in Wageningen (Fig. 4). The absence of a difference in later years could be attributed to the low level of disease incidence in catalpa. Few of the catalpa trees died (Table 1). BSD resulted in a lower percentage of dead maple plants compared with the control during the second through fourth years in Wageningen and during the second and third years in Meterik (Table 1). In Meterik, maple plants were taller in 3 of 4 years and had thicker trunks every year after BSD compared with the control, whereas catalpa plants were taller every year and thicker in the first 2 years (Table 1).

Effect of BSD on populations of plantpathogenic nematodes. The numbers of Pratylenchus spp. in the soil were significantly reduced after BSD $(P<0.01)$ and the plastic alone $(P=0.05)$ compared with the control (Fig. 5). Other plant-pathogenic nematodes were present in the soil in low numbers, and contrasts between BSD and the control and between plastic and the 
control were significant for Trichodorus spp. only $(P=0.04)$ (Fig. 5).

In maple, 230 and in catalpa 32 P. fallax per gram of root were extracted in the control treatment. These numbers were reduced by 95 to $99 \%$ after BSD (contrast maple $P<0.01$; catalpa $P=0.01$ ) (Fig. 6). This effect was still present in the second year $(P<0.01)$, although numbers extracted from maple were less than during the first year (Fig. 6). The nematode was identified as Pratylenchus fallax Seinhorst (20).

Effects of BSD on conduciveness to Verticillium wilt. Covariance analysis indicated that, after correction for the soil inoculum density of $V$. dahliae, BSD did not have higher AUDPCs than the control in any of the experimental years at either location. In other words, the BSD treatment did not significantly contribute to the model when inoculum level of $V$. dahliae was already in the model, except for maple in Meterik during the first year, where the BSD treatment had a lower AUDPC than the control $(P=0.02)$.

Effects of BSD on the percentage of nonsymptomatic plants and market value. In tree nurseries, plants with symptoms of Verticillium wilt are removed immediately and consequently are a complete loss to the grower. Therefore, the benefit of BSD compared with the control is best expressed as the percentage of plants that did not show disease symptoms during any of the four growing seasons. These percentages were significantly higher in BSD plots than in the control at Meterik, and are reflected in market values (Table 2).

\section{DISCUSSION}

Although populations of $V$. dahliae are not eliminated, BSD significantly reduces the incidence of Verticillium wilt. Application of grass or plastic alone was not effec- tive against $V$. dahliae, but plastic alone was effective in reducing soil inoculum levels of Pratylenchus spp. Reduction of soil inoculum levels of $V$. dahliae in the spring after BSD might be caused by direct killing during the BSD treatment and a weakening effect on the microsclerotia. In another study, 59\% in Wageningen and $68 \%$ in Meterik of $V$. dahliae microsclerotia were killed directly (W. J. Blok, J. G. Lamers, G. C. M. Coenen, and A. J. Termorshuizen, unpublished). The reduction in Verticillium wilt symptoms is in agreement with the $85 \%$ reduction in inoculum density observed the following spring.

The absence of treatment effects on disease development, corrected for $V$. dahliae soil inoculum densities, implies that BSD did not increase conduciveness of the soil to Verticillium wilt. Apparently, the interval between the end of the soil treatments and planting of a susceptible crop (half a year during winter) was sufficient to restore the soil biota that causes general disease suppression. It is also an indication that specific antagonists (whenever present) may not be killed by BSD. This needs to be further examined.

The densities of $P$. fallax in the roots of maple and catalpa were high in the control plots at the end of the first growing season, although preplanting densities in the soil were low. This implies that the nematode can multiply on these tree species. $P$. fallax is mainly pathogenic on grass species, but it has also been reported on rose and strawberry $(6,15,20)$, and recently on maple and catalpa (10). P. fallax has been demonstrated to lower the damage threshold for Verticillium wilt in maple (10). Because of interactions between $P$. fallax and $V$. dahliae, reduced numbers of $P$. fallax in the roots after BSD can result in a reduction in the incidence of Verticillium wilt.

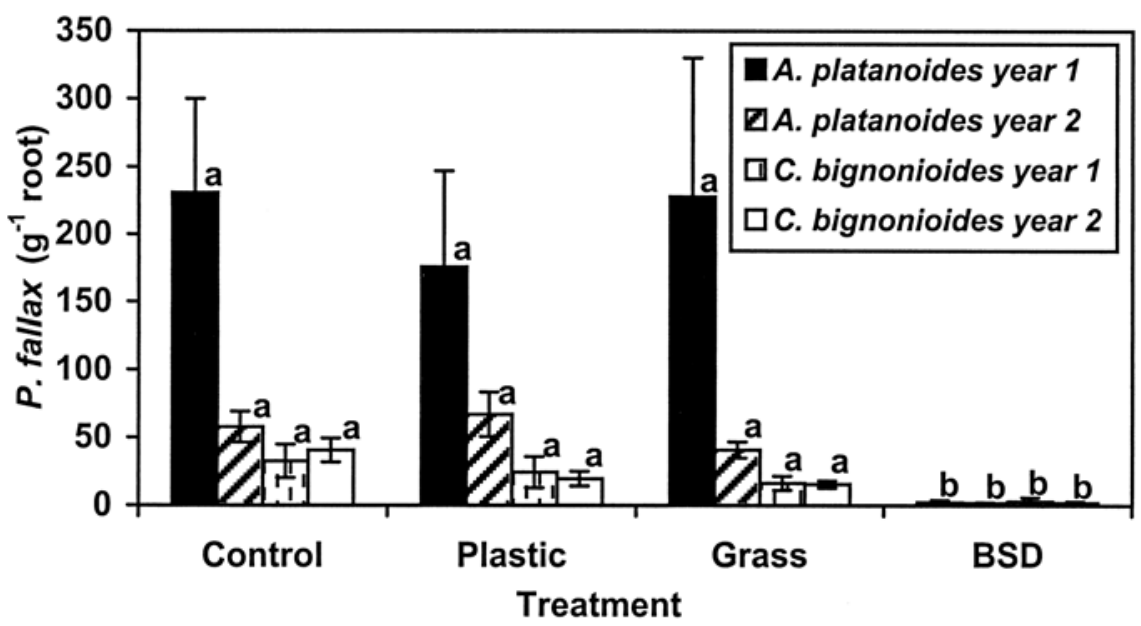

Fig. 6. Effects of the four treatments (control, plastic mulching, grass amendment, and biological soil disinfestations [BSD; grass amendment combined with plastic mulching]) on Pratylenchus fallax nematodes isolated per gram of fresh root of Acer platanoides and Catalpa bignonioides plants at the end of the first and the second growing seasons in Wageningen. Error bars indicate standard error of the mean. Bars topped by different letters within a location are significantly different $(P<0.05)$.
Generally, differences in plant growth between BSD and the control were larger in Meterik than in Wageningen, where plant stands were narrower. Catalpa is known to need more growing space than maple. This is probably the reason for the absence of significant differences in shoot length and trunk width of catalpa in Wageningen. Few catalpa plants died, because of its ability to recover from Verticillium wilt (11), but death of many maple plants in the control plots in Wageningen provided growing space for their surviving neighbors, often resulting in smaller differences in plant growth between BSD and the control than expected.

Differences in market value between BSD and the control indicate that BSD is profitable in high-value crops. Trunk width at $1 \mathrm{~m}$ and absence of Verticillium wilt are important quality measures for plant value. Although other quality criteria were not taken into account, these results provide a strong indication that BSD can serve as a method to avoid risk of yield loss in practice. Based on a commercial planting density of 30,000 plants per hectare, the benefits of BSD compared with the control were up to $€ 140,000 \mathrm{ha}^{-1}$ for maple and $€ 190,000 \mathrm{ha}^{-1}$ for catalpa (Meterik). These benefits are high compared with the direct costs of BSD. Currently, the costs for BSD are $€ 2,500$ to $7,000 \mathrm{ha}^{-1}$, but they are ex-

Table 2. Percentage of nonsymptomatic plants in each of the four growing seasons and their average market value for control treatment and biological soil disinfestation (BSD)

\begin{tabular}{|c|c|c|}
\hline Treatment & $\begin{array}{l}\text { Nonsymptomatic } \\
\text { plants }(\%)^{\mathrm{a}}\end{array}$ & $\begin{array}{c}\text { Market } \\
\text { value }(€)^{\mathbf{b}}\end{array}$ \\
\hline \multicolumn{3}{|c|}{ Wageningen } \\
\hline \multicolumn{3}{|c|}{ Acer platanoides } \\
\hline Control & 33 & 2.31 \\
\hline BSD & 69 & 4.28 \\
\hline$P$ value ${ }^{\mathrm{c}}$ & 0.06 & 0.09 \\
\hline \multicolumn{3}{|c|}{ Catalpa bignonioides } \\
\hline Control & 73 & 5.95 \\
\hline BSD & 80 & 5.73 \\
\hline$P$ value & 0.78 & 0.75 \\
\hline \multicolumn{3}{|l|}{ Meterik } \\
\hline \multicolumn{3}{|c|}{ A. platanoides } \\
\hline Control & 20 & 2.24 \\
\hline BSD & 65 & 6.96 \\
\hline$P$ value & $<0.01$ & $<0.01$ \\
\hline \multicolumn{3}{|c|}{ C. bignonioides } \\
\hline Control & 27 & 5.65 \\
\hline BSD & 63 & 11.92 \\
\hline$P$ value & $<0.01$ & $<0.01$ \\
\hline
\end{tabular}

${ }^{a}$ Living plants without disease symptoms (less than $5 \%$ of the leaves showing wilt symptoms; disease score 0 or 1 ).

${ }^{b}$ Market value was calculated for each plant (20 in Wageningen and 15 in Meterik) in the remaining row, and averaged. Economic value is based on absence of symptoms during each growing season, trunk diameter at 1-m height, and current advisory prices of the Dutch working group of roadside, forest, and park trees (H. Meijer, personal communication).

c Significance level of the difference between BSD and the control. Percentages were arcsine transformed before analysis. 
pected to drop to approx. $€ 2,000 \mathrm{ha}^{-1}$ in the near future (21).

These results show that BSD can help to decrease soil inoculum levels of $V$. dahliae and some plant-pathogenic nematodes significantly. Moreover, BSD is active against a broad range of soilborne plant pathogens (21; W. J. Blok, J. G. Lamers, G. C. M. Coenen, and A. J. Termorshuizen, unpublished). The effectiveness of the method, in combination with the absence of increased conduciveness to Verticillium wilt, makes it practically feasible and environmentally friendly. Thus, BSD can be recommended as a viable alternative to fumigation with methyl bromide.

\section{ACKNOWLEDGMENTS}

We thank the following persons for their assistance in the experiments: G. C. M. Coenen, T. van den Broek, M. Vlami, T. Lans, J. van Bezooijen, P. A. A. Looff, E. H. Bakker, J. van der Schaaf, S. K. Ispahani, H. Masselink, and J. C. van der Lippe (Wageningen University), and Th. Veens and G. A. M. Haenen (Applied Plant Research, Meterik). We thank J. G. Lamers (Applied Plant Research, Lelystad), N. G. M. Dolmans, R. W. M. van Tol, H. Meijer, and J. A. Hiemstra (Applied Plant Research, Boskoop) for valuable suggestions on the experiments. This work was supported by the Product Board for Horticulture, the Netherlands, and by the European Commission Framework Program 5 (project QLRT-1999-1523: Verticillium wilt in trees).

\section{LITERATURE CITED}

1. Anonymous. 1990. Report of the Working Group Tree Culture. Background Document of the Multiple Year Crop Protection Plan. Ministry of Agriculture, Nature and Fishery, Den Haag, The Netherlands. (In Dutch.) p. 14

2. Ashworth, L. J., Morgan, D. P., Gaona, S. A., and McCain, A. H. 1982. Polyethylene tarping controls verticillium wilt in pistachios. Calif. Agric. 36(5-6):17-18
3. Blok, W. J., Lamers, J. G., Termorshuizen, A. J., and Bollen, G. J. 2000. Control of soilborne plant pathogens by incorporating fresh organic amendments followed by tarping. Phytopathology 90:253-259.

4. Campbell, C. L., and Madden, L. V. 1990. Introduction to Plant Disease Epidemiology. John Wiley \& Sons, New York. pp. 192-194.

5. Cody, R. P., and Smith, J. K. 1997. Applied Statistics and the SAS Programming Language. 4th ed. Prentice Hall, Upper Saddle River, NJ. pp. 174-178.

6. Coolen, W. A., and Hendrickx, G. J. 1972. Monograph on the Nematological Situation in Belgian Rose Culture. Publikatie-nr. W-10. (In Dutch.) Governmental Station for Nematology and Entomology, Merelbeke, Belgium. pp. 1-29.

7. Corsten, R., Roelofs, T., and de Veld, P. 2002. Tackling Verticillium problems in chrysanthemum. (In Dutch.) Vakbl. Bloemisterij 57(29):42-43.

8. Duniway, J. M. 2002. Status of chemical alternatives to methyl bromide for pre-plant fumigation of soil. Phytopathology 92:13371343.

9. Dwinell, L. D., and Sinclair, W. A. 1967. Effects of N, P, K, and inoculum density of Verticillium dahliae on populations of Pratylenchus penetrans in roots of American elm and sugar maple. (Abstr.) Phytopathology $57: 810$.

10. Goud, J. C. 2003. Verticillium Wilt in Trees. Detection, Prediction and Disease Management. Ph.D. thesis. Wageningen University, Wageningen, The Netherlands. pp. 73-86.

11. Goud, J. C., and Termorshuizen, A. J. 2002. Pathogenicity and virulence of the two Dutch VCGs of Verticillium dahliae to woody ornamentals. Eur. J. Plant Pathol. 108:771-782.

12. Harris, D. C., Yang, J. R., and Ridout, M. S. 1993. The detection and estimation of Verticillium dahliae in naturally infested soil. Plant Pathol. 42:238-250.

13. Katan, J., Greenberger, A., Alon, H., and Grinstein, A. 1976. Solar heating by polyethylene mulching for the control of diseases caused by soil-borne pathogens. Phytopathology 66:683-688.
14. Martin, M. J., Riedel, R. M., and Rowe, R. C. 1982. Verticillium dahliae and Pratylenchus penetrans: Interactions in the early dying complex of potatoes in Ohio. Phytopathology 72:640-644

15. McKinley, R. T., and Talboys, P. W. 1979 Effects of Pratylenchus penetrans on development of strawberry wilt caused by Verticillium dahliae. Ann. Appl. Biol. 92:347-357.

16. Mus, A., and Huygen, C. 1992. Methyl Bromide. The Dutch Environmental Situation and Policy. TNO. Institute of Environmental Sciences, Apeldoorn, The Netherlands. pp. 1-19.

17. Oostenbrink, M. 1960. Estimating nematode populations by some selected methods. Pages 85-102 in: Nematology. J. N. Sasser and W. R. Jenkins, eds. University of North Carolina Press, Chapel Hill, NC

18. Pegg, G. F., and Brady, B. L. 2002. Verticillium Wilts. CABI Publishing, Wallingford, UK. pp. 293-340.

19. Pullman, G. S., and DeVay, J. E. 1982. Effect of soil flooding and paddy rice culture on the survival of Verticillium dahliae and incidence of verticillium wilt in cotton. Phytopathology 72:1285-1289.

20. Seinhorst, J. W. 1977. Pratylenchus fallax Pages 1-2 in: C.I.H.-Descriptions of Plantparasitic Nematodes Set 7, No. 100. Institute for Research on Plant Pathology, Wageningen, The Netherlands.

21. Sikken, K. 2003. Suffocating fungi and nematodes with biomass and foil. (In Dutch.) Oogst 16(30/31):34-35.

22. Sinclair, W. A., Lyon, H. H., and Johnson, W. T. 1989. Diseases of Trees and Shrubs. Comstock Publishing Associates, Cornell University Press, Ithaca, NY. pp. 374-377.

23. Stover, R. H. 1979. Flooding of soil for disease control. Pages 19-28 in: Soil Disinfestation. D. Mulder, ed. Elsevier Scientific Publishing Company, Amsterdam, The Netherlands.

24. Wheeler, T. A., Madden, L. V., Riedel, R. M., and Rowe, R. C. 1994. Distribution and yieldloss relations of Verticillium dahliae, Pratylenchus penetrans, $P$. scribneri, $P$. crenatus, and Meloidogyne hapla in commercial potato fields. Phytopathology 84:843-852. 